\title{
SOME OPTIMAL CULTURE CONDITIONS FOR PRODUCTION OF CYCLOSPORIN A BY FUSARIUM ROSEUM
}

\author{
Ahmed A. Ismaiel*, El-Sayed A. El-Sayed, Asmaa A. Mahmoud
}

Department of Botany, Faculty of Science, Zagazig University, Zagazig, Egypt

Submitted: June 30, 2009; Returned to authors for corrections: March 10, 2010; Approved: June 21, 2010.

\begin{abstract}
A suitable chemically defined culture medium was selected and some optimal conditions for the production of the highly immunosuppressive compound, cyclosporin A (Cyc A) are reported. Medium of the following composition was favorable for the production of Cyc A by Fusarium roseum: glucose, 30; $\mathrm{NaNO}_{3}, 2 ; \mathrm{KH}_{2} \mathrm{PO}_{4}, 1 ; \mathrm{MgSO}_{4} .7 \mathrm{H}_{2} \mathrm{O}, 0.5$ and $\mathrm{KCL}, 0.5(\mathrm{~g} / \mathrm{l})$. Maximum productivity of Cyc A was achieved at $\mathrm{pH} 6.0$ when $50 \mathrm{ml}$ of the fermentation medium $/ 250 \mathrm{ml}$ flask, inoculated with five fungal agar discs (6 mm, diameter) of 7-days old $F$. roseum culture after incubation at $30^{\circ} \mathrm{C}$ at $120 \mathrm{rpm}$ for 7 days.
\end{abstract}

Key words: Fusarium roseum, Cyclosporin A, Fermentation conditions.

\section{INTRODUCTION}

Cyclosporins are a family of neutral, highly lipophilic, cyclic undecapeptides containing unusual amino acids $(36,37)$. They can be produced in a fungal fermentation process by aerobic filamentous fungi which were originally classified as Trichoderma polysporum (Link ex Pers.) Rifai (12) and more recently as Tolypocladium inflatum W. Gams (16) or Beauveria nivea Von Arx (35).

Cyclosporin A (Cyc A, Figure 1), the main representative of the series, is a potent antifungal and immunosuppressive compound $(7,17)$ that has been widely used to diminish transplant rejection (6) and control some autoimmune diseases (33).

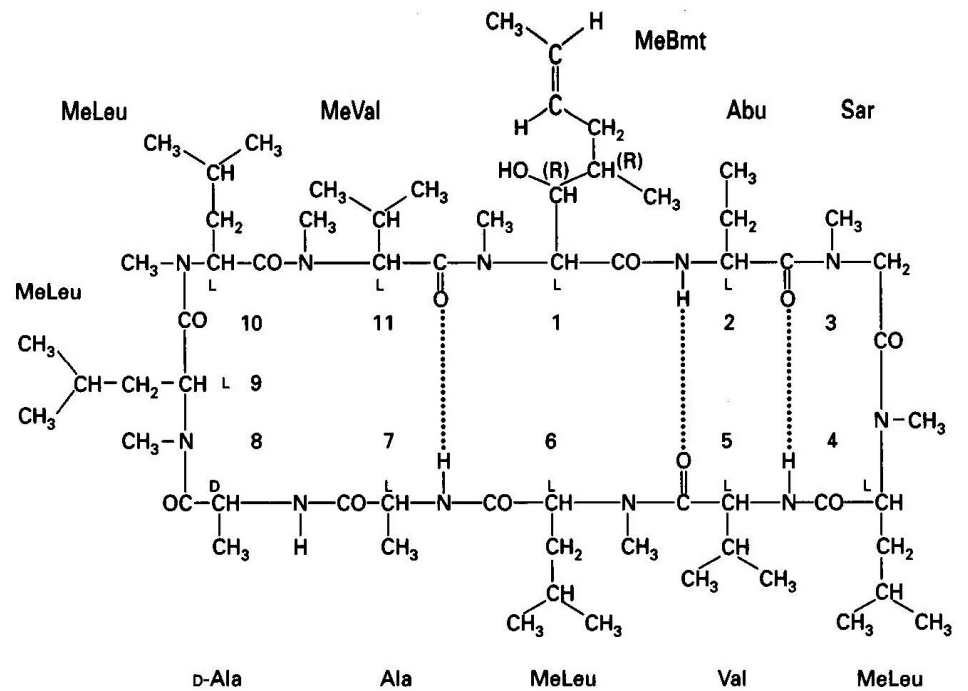

Figure 1. Structure of cyclosporin A as established by Dreyfuss et al. (12)

*Corresponding Author. Mailing address: Botany Depart., Faculty of Science, Zagazig University, Zagazig, Egypt..; E-mail: microbiologist_80@ yahoo.com 
Cyc A biosynthesis is catalyzed by a single multienzyme polypeptide (20), the so-called cyclosporin synthetase which has a molecular mass of about $1400 \mathrm{KDa}$ (30). This enzyme synthesizes Cyc A by a thiotemplate mechanism starting from the precursor amino acids in their unmethylated form (20).

Many attempts have been made to optimize Cyc A production, including immobilization (32) and solid state fermentation (26). However, even though the enzymatic production of cyclosporin has already been established and proven (5), submerged fermentation production is normally used, owing to the complexity involved in enzymatic synthesis. The organisms that are known to produce Cyc A include Tolypocladium inflatum (14), Fusarium solani (29) Neocosmospora varinfecta (24) and Aspergillus terreus (28). In this paper, we briefly describe the optimum fermentation conditions and medium requirements necessary for Cyc A production by Fusarium roseum, a microorganism that has not yet been studied for this target.

\section{MATERIALS AND METHODS}

\section{Microorganism}

Fusarium roseum CZ1 was locally isolated from a soil sample cultivated with clover (Trifolium alexanderinum) and identified to the species level according to Booth (8) and Domsch et al. (13). Potato dextrose agar (PDA) was used for isolation and maintenance of the experimental fungus.

\section{Cultivation Conditions}

To select the proper fermentation medium which supports successful Cyc A production, a total of six types of media (Table 2) differing in the composition of their constituents were tested. A fungal agar disc (6 mm, diameter) of 7-days old culture was introduced into a $250 \mathrm{ml}$ flask containing $50 \mathrm{ml}$ of the autoclaved broth medium. The culture flasks were incubated at $30^{\circ} \mathrm{C}$ for 7 days. In the effort to increase Cyc A yields, several experimental conditions were tried. The effect of physical factors including agitation rates of incubation at 120 and $200 \mathrm{rpm}$, different fermentation periods varied from 2 to 16 days, a range of initial $\mathrm{pH}$ values of the medium varied from 2.0 to 9.0 , different numbers of inoculated fungal agar discs varied from 1.0 to 5.0 and different volumes of the cultivation medium at 25 to $100 \mathrm{ml}$ in $250 \mathrm{ml}$ capacity flask, were investigated.

In the experimental series, ten different compounds were tried individually as carbon sources. These compounds were arabinose, glucose, galactose, glycerol, mannitol, maltose, lactose, sucrose, cellulose, and starch. All were used at 3\% concentration, the same as that of sucrose in the original yeast extract-supplemented Czapek-Dox's medium. Different concentrations of the most productive carbon sources varied from $2 \%$ to $6 \%(\mathrm{w} / \mathrm{v})$ were tested. Eight different nitrogen sources including organic and inorganic ones were added individually to the medium as substitutes for yeast extract. Substitution of yeast extract by nitrogenous sources was done in an equal nitrogen basis. These nitrogen sources were peptone, casein, soybean meal, yeast extract, ammonium chloride, ammonium sulfate, sodium nitrate, and potassium nitrate. Different concentrations of the most productive nitrogen source were also investigated.

Table 2. Suitability of different fermentation media for the production of Cyc A by F. roseum.

\begin{tabular}{lll}
\hline \multicolumn{1}{c}{ Medium } & \multicolumn{1}{c}{$\begin{array}{c}\text { Dry cell } \\
\text { weights }\left(\mathbf{g l}^{-1}\right)\end{array}$} & $\begin{array}{c}\text { Cyc A levels } \\
\left(\mathbf{m g l} \mathbf{-}^{\mathbf{1}}\right)\end{array}$ \\
\hline I- Czapek-Dox's & $2.86 \pm 0.4$ & $7.72 \pm 1.16$ \\
II- Czapek-Dox's supp. with & $4.16 \pm 0.2$ & $11.45 \pm 0.54$ \\
0.5 \% yeast extract & & \\
III- Malt-yeast & $4.10 \pm 0.6$ & $10.38 \pm 1.14$ \\
IV- Yeast-sucrose & $7.58 \pm 0.2$ & $9.01 \pm 1.31$ \\
V- Glucose-Czapek-Dox's & $5.34 \pm 0.6$ & $8.55 \pm 1.43$ \\
supp. with 1\% bactopeptone & & \\
VI- Sabouraud's-glucose & $3.40 \pm 0.4$ & $8.16 \pm 1.20$
\end{tabular}

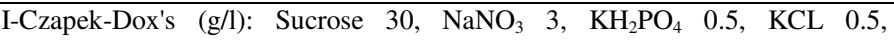
$\mathrm{MgSO}_{4} .7 \mathrm{H}_{2} \mathrm{O} 0.5, \mathrm{FeSO}_{4} 7 \mathrm{H}_{2} \mathrm{O} 0.01$.

II-Czapek-Dox's supp. with $0.5 \%$ yeast extract: Medium I with $5 \mathrm{~g}$ yeast extract instead of $\mathrm{NaNO}_{3}$.

III- Malt-yeast (g/l): Malt extract 20, yeast extract 4

IV- Yeast-sucrose (g/l): Sucrose 50, yeast extract 20.

V- Glucose-Czapek-Dox's supp. with $1 \%$ bactopeptone (g/l): Glucose 50, $\mathrm{KH}_{2} \mathrm{PO}_{4}$ 5, bactopeptone 10, KCL 2.5 .

VI- Sabouraud's-glucose (g/l): Bactopeptone 10, glucose 20, $\mathrm{MgSO}_{4} .7 \mathrm{H}_{2} \mathrm{O} 1.0$, $\mathrm{KH}_{2} \mathrm{PO}_{4} 1.0$. Initial $\mathrm{pH}$ value: 6.0 . 


\section{Analytical Methods}

Determination of Dry Cell Weight: Culture broth $(50 \mathrm{ml})$ was filtered through preweighted Whatman No.1 filter papers. The cells were then dried at $80^{\circ} \mathrm{C}$ to a constant weight prior to measuring dry weight.

Extraction of Cyc A from $F$. roseum Culture: The methods of extraction and analysis were adopted according to Sawai et al. (29), which can be summarized, as follows: the culture filtrate was extracted three times with equal volumes of ethyl acetate, shaked for about 30 minutes and allowed to stand for 30 minutes. The ethyl acetate layer washed three times with $5 \%$ sodium bicarbonate solution and then twice with water. The solvent layer was taken and dried over anhydrous $\mathrm{Na}_{2} \mathrm{SO}_{4}$, then evaporated under vaccum till dryness. The resultant dried crud extract was dissolved in methanol and undergone the necessary chromatographic analysis.

Qualitative and Quantitative Determination of CycA: Cyc A was determined qualitatively and quantitatively according to the method described by Dreyfuss et al. (12) using precoated thin layer chromatographic (TLC) plates with silica gel GF-254. The methanol extract samples and authentic Cyc A (Sandimmun, Novartis Pharma AG, Basle, Switzerland) were spotted on the chromatograms and developed in n-hexane solution then redeveloped in the solvent system of benzeneisopropanol (9:1). Cyc A spots $\left(\mathrm{R}_{\mathrm{f}}=0.37\right)$ give violet influorescence under short wave length ultraviolet rays. Detection of spots was more clearly after staining with iodine vapour. The sopts were scraped and then dissolved in a known volume of methanol and the absorption was then measured using an ultraviolet spectrophotometer (Spectronic 21 DMolton Roy) at $230 \mathrm{~nm}$. Amounts of Cyc A were then estimated from a standard curve. The identity of Cyc A was also confirmed by ${ }^{1} \mathrm{H}$ NMR spectroscopic analysis which was kindly performed in the Microanalytical Unit of the Cairo University, Giza, Egypt. The spectra were recorded in $\mathrm{CDCL}_{3}$ at $25{ }^{\circ} \mathrm{C}$ with a Varian Gemini-200 spectrometer (Varian, UK) at $200 \mathrm{MHz}$ using tetramethylsilane as an internal reference. Chemical shifts are expressed in ppm $(\delta)$ units.
All experemints were conducted in triplicates and the mean \pm standard deviation (SD) of these triplicates was calculated.

\section{RESULTS}

\section{${ }^{1}$ H NMR Spectra}

In the present study, the resultant crystalline Cyc A from F. roseum cultures was subjected to ${ }^{1} \mathrm{H}$ NMR analysis after submerged cultivation of the experimental fungus, followed by extraction of the filtrate with ethyl acetate and chromatographic separation. The chemical shifts are expressed in ppm $(\delta)$ units, recorded in Table 1. The ${ }^{1} \mathrm{H}$ NMR spectrum of Cyc $\mathrm{A}$ in $\mathrm{CDCL}_{3}$ showed four $\mathrm{N}-\mathrm{H}$ amide protons as doublets at 7.26 ppm, seven $\mathrm{N}$-methyl signals (two are singlets at 3.47 and 3.37 ppm and five are doublets between 2.98 and $3.29 \mathrm{ppm}$ ) and one formed $\mathrm{O}-\mathrm{H}$ group as doublet at $3.647 \mathrm{ppm}$. The aliphatic $\alpha$ protons resonate between 3.60 to $3.70 \mathrm{ppm}$, the $\beta$-protons in the range of 1.12 to $3.68 \mathrm{ppm}$, while $\delta$ - and $\gamma$-protons resonate in the range of 0.841 to $3.66 \mathrm{ppm}$.

\section{Optimization of Cultural Conditions}

Suitability of the Cultivation Medium: The results given in Table 2 indicate that Czapek-Dox's broth medium supplemented with $0.5 \%$ yeast extract proved to be the most suitable and conductive medium for the production process where it yeilded $11.45 \mathrm{mg} \mathrm{Cyc} \mathrm{A} / 1$. However, the maximum mycelium growth $(7.58 \mathrm{~g} / \mathrm{l})$ was recorded on yeast-sucrose broth medium. Therefore, yeast extract supplemented CzapekDox's medium was used as a working medium throughout the present study.

Our results indicated that high concentration of the synthesized Cyc A by the experimental organism was produced in the culture filtrate $(11.45 \mathrm{mg} / \mathrm{l})$ and a lower level was produced in the fungal mycelia $(1.51 \mathrm{mg} / \mathrm{g}$ biomass) after cultivation of the fungus in yeast extract supplemented CzapekDox's medium for 7 days at $30{ }^{\circ} \mathrm{C}$. Hence, the present study was directed to optimize the production of Cyc A from the culture filtrate of the experimental organism. 
Table 1. ${ }^{1} \mathrm{H}-\mathrm{NMR}(200 \mathrm{MHz})$ data of Cyc A $\left(\mathrm{CDCL}_{3}, 25^{\circ} \mathrm{C}\right)$.

\begin{tabular}{|c|c|c|}
\hline Atom & $\boldsymbol{\delta}_{\mathbf{H}}$ & Multi. \\
\hline $\mathrm{N}-\mathrm{CH}_{3}$ & 3.472 & $\mathrm{~s}$ \\
\hline $1 \alpha$ & 3.704 & $\mathrm{~d}$ \\
\hline $1 \beta$ & 3.687 & $\mathrm{~m}$ \\
\hline $1 \gamma$ & 3.662 & $\mathrm{~d}$ \\
\hline $1 \gamma-\mathrm{CH}_{3}$ & 0.841 & $\mathrm{~d}$ \\
\hline $1 \delta$ & 1.168 & $\mathrm{~m}$ \\
\hline $1 \gamma-\mathrm{OH}$ & 3.647 & $\mathrm{~d}$ \\
\hline 2-NH & 7.264 & $\mathrm{~d}$ \\
\hline $2 \alpha$ & 3.662 & $\mathrm{~m}$ \\
\hline $2 \beta$ & 1.163 & $\mathrm{t}$ \\
\hline $\mathrm{N}-\mathrm{CH}_{3}$ & 3.378 & $\mathrm{~s}$ \\
\hline $3 \alpha$ & 3.604 & $\mathrm{~s}$ \\
\hline $\mathrm{N}-\mathrm{CH}_{3}$ & 3.222 & d \\
\hline $4 \alpha$ & 3.444 & $\mathrm{t}$ \\
\hline \multirow[t]{2}{*}{$4 \beta$} & 1.134 & $\mathrm{~m}$ \\
\hline & 2.982 & $\mathrm{~m}$ \\
\hline $4 \gamma$ & 1.168 & $\mathrm{~m}$ \\
\hline $4 \delta_{1}$ & 0.841 & $\mathrm{~d}$ \\
\hline $4 \delta_{2}$ & 1.098 & d \\
\hline $5-\mathrm{NH}$ & 7.264 & d \\
\hline $5 \alpha$ & 3.70 & $\mathrm{~d}$ \\
\hline $5 \beta$ & 2.982 & $\mathrm{~m}$ \\
\hline $5 \gamma_{1}$ & 1.098 & $\mathrm{~d}$ \\
\hline $5 \gamma_{2}$ & 1.134 & d \\
\hline $\mathrm{N}-\mathrm{CH}_{3}$ & 3.296 & d \\
\hline $6 \alpha$ & 3.704 & $\mathrm{t}$ \\
\hline $6 \beta$ & 1.134 & $\mathrm{~m}$ \\
\hline $6 \gamma$ & 1.06 & $\mathrm{~m}$ \\
\hline $6 \delta_{1}$ & 0.841 & $\mathrm{~d}$ \\
\hline $6 \delta_{2}$ & 0.841 & d \\
\hline 7-NH & 7.264 & $\mathrm{~d}$ \\
\hline $7 \alpha$ & 3.687 & $\mathrm{~m}$ \\
\hline $7 \beta$ & 1.168 & $\mathrm{~d}$ \\
\hline 8-NH & 7.268 & $\mathrm{~d}$ \\
\hline $8 \alpha$ & 3.70 & $\mathrm{~m}$ \\
\hline $8 \beta$ & 1.168 & $\mathrm{~d}$ \\
\hline $\mathrm{N}-\mathrm{CH}_{3}$ & 3.164 & d \\
\hline $9 \alpha$ & 3.704 & $\mathrm{t}$ \\
\hline $9 \beta$ & 1.134 & $\mathrm{t}$ \\
\hline $9 \gamma$ & 1.168 & $\mathrm{~m}$ \\
\hline $9 \delta_{1}$ & 0.841 & $\mathrm{~d}$ \\
\hline $9 \delta_{2}$ & 0.841 & d \\
\hline $\mathrm{N}-\mathrm{CH}_{3}$ & 2.982 & $\mathrm{~d}$ \\
\hline $10 \alpha$ & 3.70 & $\mathrm{t}$ \\
\hline $10 \beta$ & 1.123 & $\mathrm{t}$ \\
\hline $10 \gamma$ & 1.168 & $\mathrm{~m}$ \\
\hline $10 \delta_{1}$ & 0.841 & $\mathrm{~d}$ \\
\hline $10 \delta_{2}$ & 0.841 & $\mathrm{~d}$ \\
\hline $\mathrm{N}-\mathrm{CH}_{3}$ & 2.982 & $\mathrm{~d}$ \\
\hline $11 \alpha$ & 3.704 & $\mathrm{~d}$ \\
\hline $11 \beta$ & 1.168 & $\mathrm{~m}$ \\
\hline $11 \gamma_{1}$ & 0.841 & $\mathrm{~d}$ \\
\hline $11 \gamma_{2}$ & 0.841 & $\mathrm{~d}$ \\
\hline
\end{tabular}




\section{Effects of Static and Agitation Conditions of}

Incubation: With regard to the nature of the fungus growth, it was observed that the agitation rate at $200 \mathrm{rpm}$ showed an increase in fungal pellets more than those recorded in case of the agitation rate at $120 \mathrm{rpm}$. The results showed that the dry cell weights produced either at the agitation rate $120 \mathrm{rpm}$ or $200 \mathrm{rpm}$ were higher than those produced at static conditions (data not shown). The best Cyc A yield (18.15 mg/ 1) was obtained at $120 \mathrm{rpm}$, however no detectable amount of Cyc A was determined at $200 \mathrm{rpm}$. The static conditions produced approximately $59 \%$ of the concentration of Cyc A produced at $120 \mathrm{rpm}$.
Time Course of Cyc A Production: F. roseum was cultured in Czapek-Dox's broth medium supplemented with 0.5 $\%$ yeast extract and incubated at $30^{\circ} \mathrm{C}$ in a shaking incubator at $120 \mathrm{rpm}$. The time course profile of Cyc A production is shown in Figure 2. Any increase in the growth period was accompanied with a clear increase in the values of both dry cell weights and Cyc A till maximum values (11.16 g dry cell weight / 1 and $18.43 \mathrm{mg} \mathrm{Cyc} \mathrm{A} \mathrm{/} \mathrm{1)} \mathrm{were} \mathrm{obtained} \mathrm{at} 14$ and 7 days, respectively; then a decline was obtained in both parameters with increasing of the growth periods. So that, the experimental fungus was grown for 7 days in the subsequent experiments throughout the present work.

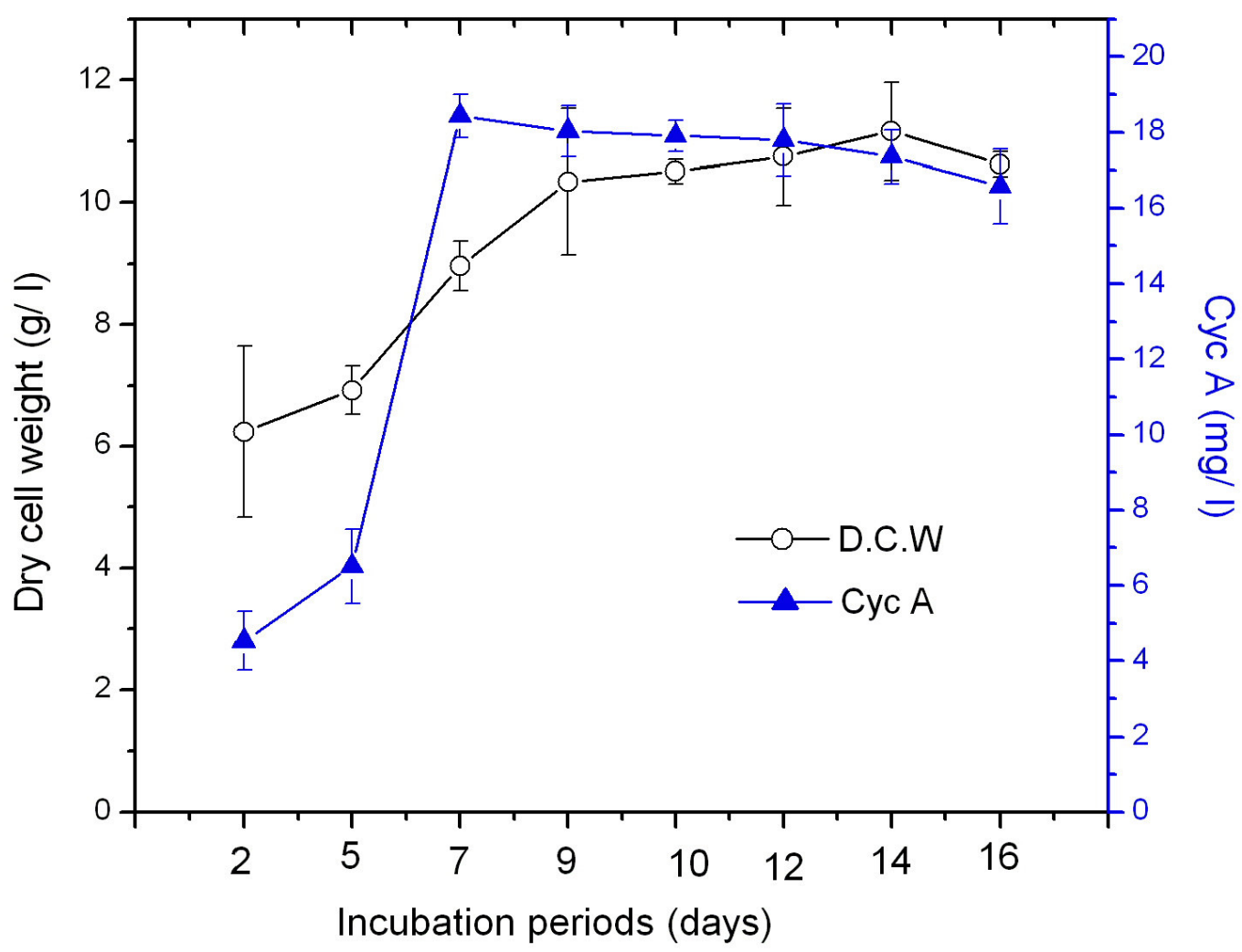

Figure 2. Effects of different fermentation periods on the production of Cyc A using F. roseum. 
Effects of Incubation Temperature: The results given in Figure 3 show that the optimum incubation temperature for maximum values of dry cell growth $(8.54 \mathrm{~g} / \mathrm{1})$ and Cyc A (18.94 mg/ 1) was $30{ }^{\circ} \mathrm{C}$, afterwhich a gradual decreases were obtained in both parameters with the increase of incubation temperature to 35 and $40{ }^{\circ} \mathrm{C}$.

Effects of Initial pH: The initial pH of the medium was adjusted to a range of $2.0-9.0$ by adding varying amounts of 1
$\mathrm{N} \mathrm{HCL}$ and $1 \mathrm{~N} \mathrm{NaOH}$. In most cases, final $\mathrm{pH}$ values were between 3.4 and 4.6. It is obvious that the values of dry cell weights and Cyc A increased with the increase of initial $\mathrm{pH}$ values, reaching a maximum for both parameters at $\mathrm{pH} 6.0$ and then decreased at the higher $\mathrm{pH}$ values, (Figure 4). Culture medium of $\mathrm{pH} 6.0$ was selected for further investigation throughout this work.

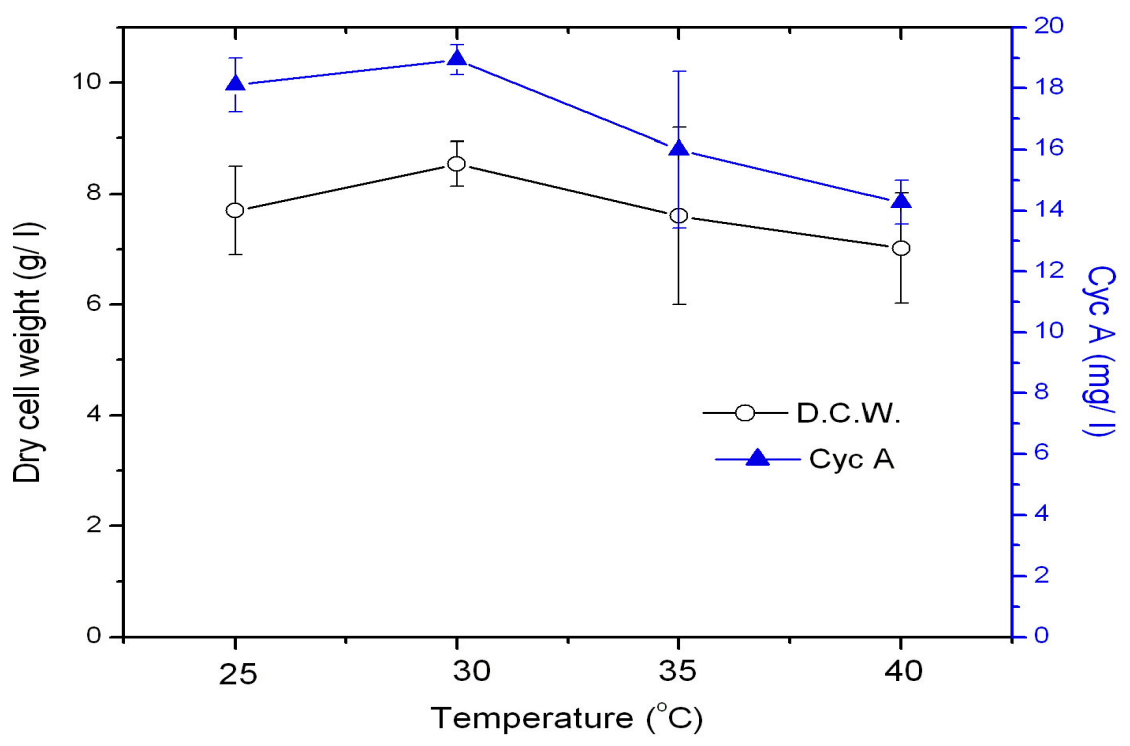

Figure 3. Cyc A production by $F$. roseum grown under different incubation temperatures.

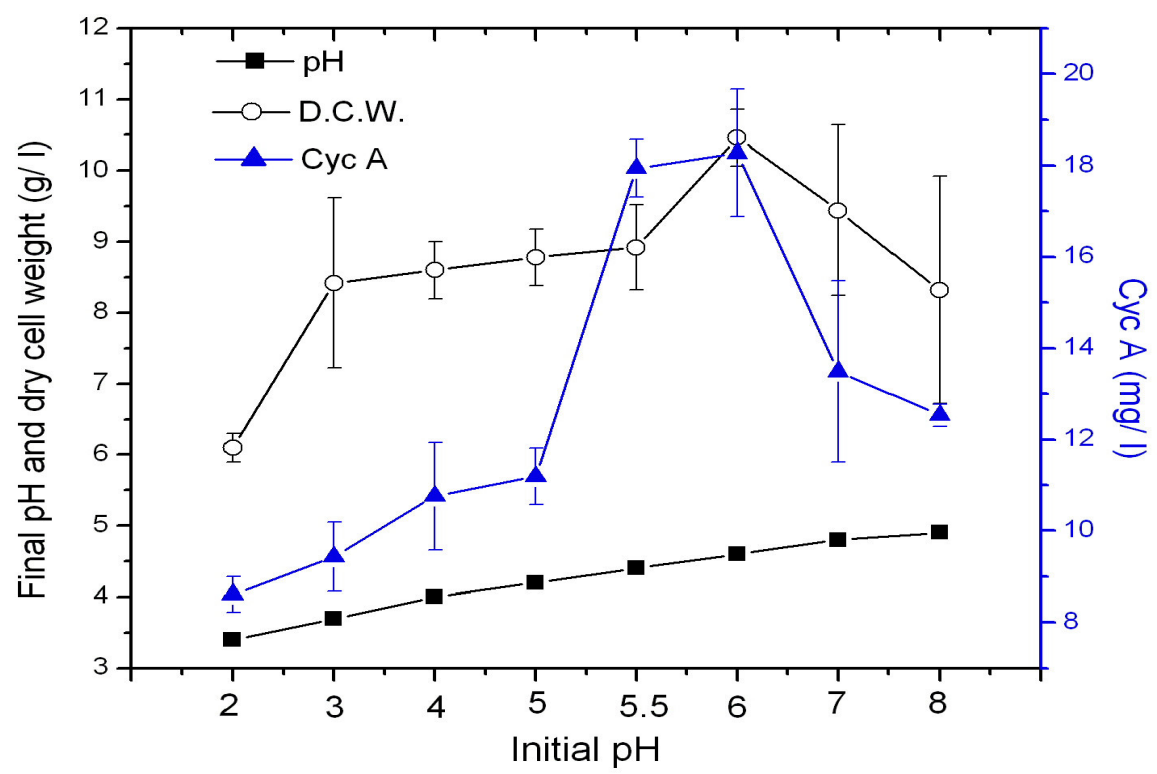

Figure 4. Effects of initial $\mathrm{pH}$ on the production of Cyc A by F. roseum. 
Numbers of Inoculum Culture Discs: Agar discs (6 mm, diameter) of 7 days old $F$. roseum culture were inoculated in different numbers varied from 1 to 6 into yeast extract supplemented Czapek-Dox's broth. In particular, the results showed that the increases in the numbers of inoculum discs were associated with increases in the productivity of Cyc A (data not shown). The maximum concentration of $\mathrm{Cyc} \mathrm{A}$ obtained was $21.7 \mathrm{mg} / \mathrm{l} \sim 1.09 \mathrm{mg} / 50 \mathrm{ml}$ when the medium was inoculated with 5 fungal agar discs, after which the Cyc A productivity began to decrease when the medium was inoculated with 6 fungal agar discs. The highest dry cell weights $(10.46 \mathrm{~g} / \mathrm{l} \sim 0.523 \mathrm{mg} / 50 \mathrm{ml})$ were obtained when the medium was inoculated with single fungal agar disc after which, the values were decreased gradually with the increase of numbers of inoculum discs.

Effects of the Medium Volume: It is evident from Figure 5 that the dry cell weights increased with the increase in culture volume till maximum values $(9.54 \mathrm{~g} / \mathrm{l})$ when a $250 \mathrm{ml}$-flask containing $75 \mathrm{ml}$ fermentation medium was used. The highest Cyc A level (22.46 mg/ 1) was obtained by using 250 ml-flask containing production medium equal to $50 \mathrm{ml}$, afterwhich; the further increase in the size of the fermentation medium to $75 \mathrm{ml}$ or $100 \mathrm{ml} / 250 \mathrm{ml}$ flask is accompanied with a decrease in the Cyc A concentration.

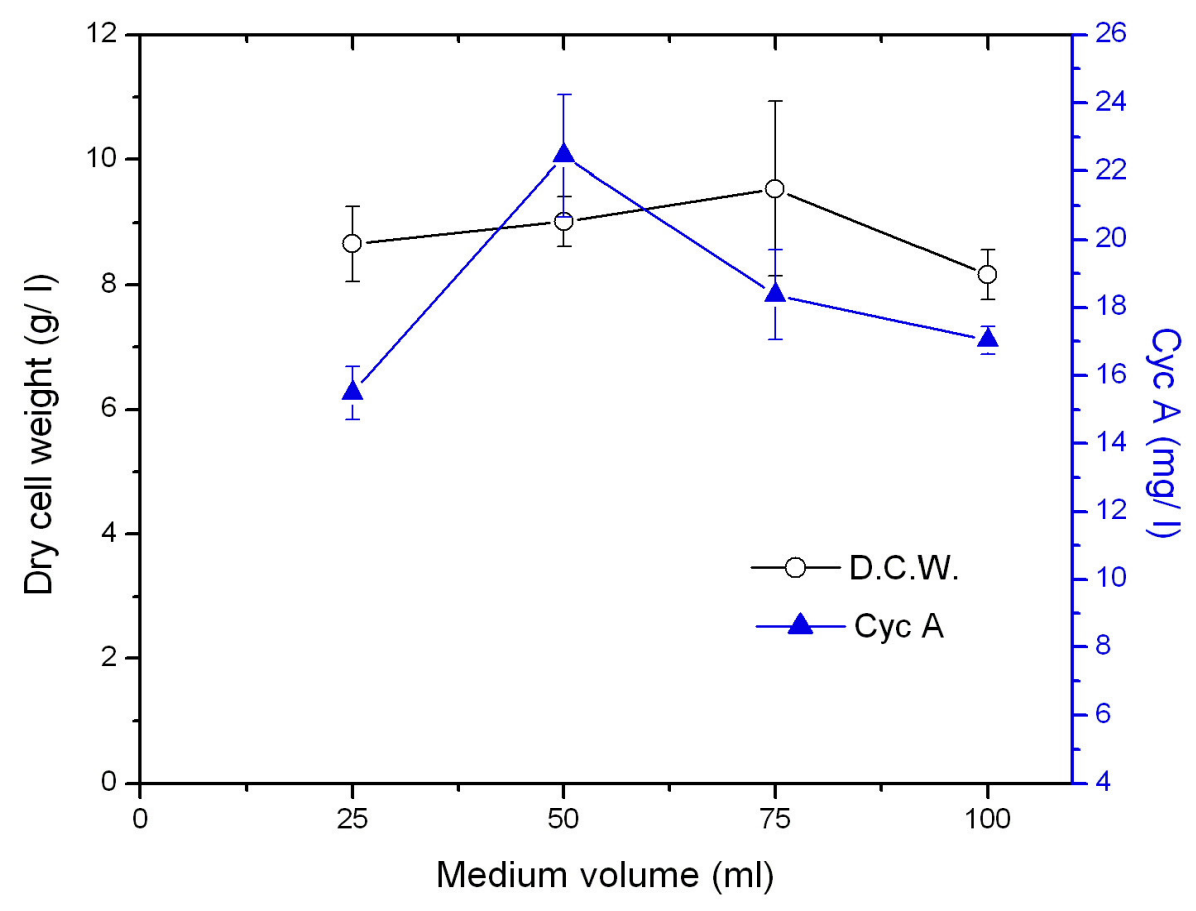

Figure 5. Cyc A production by $F$. roseum grown under different volumes of cultivation medium.

Effects of Carbon Sources: The effects of various carbon sources on the production of Cyc A were investigated (Table 3). Glucose was found to be the most effective substrate among the carbon sources used, and the highest Cyc A concentration obtained was $22.90 \mathrm{mg} / 1$. Sucrose produced also a satisfactory amounts of Cyc A $(22.5 \mathrm{mg} / \mathrm{l})$ followed by galactose which gave a concentration of Cyc A, approximately twice that obtained with cellulose. Although the experimental fungus produced a low level of Cyc A when arabinose was used as a carbon substrate, but it gave a maximal cell mass (10.88 g/ 1) on the same substrate. Maltose was also a good substrate for growth of the fungus and produced $98 \%$ of the dry cell weight produced by arabinose.

Effects of Glucose Concentrations: Different 
concentrations of glucose $(2.0-6.0 \%, \mathrm{w} / \mathrm{v})$ were added to medium containing $0.5 \%(\mathrm{w} / \mathrm{v})$ yeast extract. The maximum concentration of Cyc A (23.38 mg/ 1) was recorded at $3.0 \%$ of glucose, which was followed by a sharp decrease (16.26 and $16.22 \mathrm{mg} / \mathrm{l})$ at higher glucose concentrations (5.0 and $6.0 \%$, respectively). Dry cell weights increased as glucose concentrations increased till a maximum value (13.44 g/ 1) at $5.0 \%$ glucose concentration. Dry cell weights obtained at 6.0 $\%$ glucose represented, approximately $95.5 \%$ of that produced at $5.0 \%$. However, dry cell weights recorded at $2.0 \%$ was approximately, $62.5 \%$ of that produced at $5.0 \%$ (Figure 6).

Effects of Nitrogen Sources: Various organic and inorganic nitrogen sources were added (as equivalent to $5.0 \mathrm{~g} / 1$ of yeast extract) separately to the modified medium containing $3.0 \%$ (w/v) glucose. The highest Cyc A level (25.41 mg/ 1) was obtained on sodium nitrate compared with that produced on the tested nitrogen sources (Table 3). It is shown that the growth of F. roseum is not associated with Cyc A production because when soybean meal was used as a nitrogen source, the cell mass was maximum (12.2 g / ), however Cyc A production was minimum $(12.01 \mathrm{mg} / \mathrm{1})$. Sodium nitrate as a substrate for growth produced $92 \%$ of the dry cell weights produced by potassium nitrate, while the concentration of Cyc A produced in the presence of potassium nitrate was $93 \%$ of that produced in the presence of sodium nitrate, although both of them are nitrate nitrogen sources. With respect to the effect of organic nitrogenous sources on $F$. roseum growth, yeast extract produced approximately $74 \%$ of the cell mass produced by soybean meal, while the concentration of Cyc A produced by yeast extract was approximately twice of that obtained with soybean meal. Yeast extract as an organic nitrogenous substrate for growth and Cyc A production by $F$. roseum was more favorable than peptone and casein. With regard to the effect of ammonium nitrogen sources on growth and Cyc A production by $F$. roseum, ammonium sulphate gave a higher cell mass than that obtained with ammonium chloride, while the contrary took place in case of Cyc A production because the fungus produced higher concentration of $\mathrm{Cyc} \mathrm{A}$ in presence of ammonium chloride than that produced in the presence of ammonium sulfate.

Table 3. Effects of carbon and nitrogen sources on cell mass and Cyc A production.

\begin{tabular}{|c|c|c|}
\hline Carbon and nitrogen sources & Dry cell weights $\left(\mathrm{gl}^{1}{ }^{1}\right)$ & Cyc A levels (mgl- $\left.{ }^{1}\right)$ \\
\hline Arabinose & $10.88 \pm 0.60$ & $10.07 \pm 1.19$ \\
\hline Glucose & $9.00 \pm 0.60$ & $22.91 \pm 1.13$ \\
\hline Galactose & $10.08 \pm 0.80$ & $19.53 \pm 1.04$ \\
\hline Glycerol & $9.84 \pm 0.60$ & $12.88 \pm 1.55$ \\
\hline Mannitol & $9.14 \pm 0.40$ & $12.11 \pm 1.56$ \\
\hline Maltose & $10.66 \pm 0.40$ & $14.52 \pm 0.38$ \\
\hline Lactose & $9.08 \pm 0.20$ & $13.93 \pm 3.36$ \\
\hline Sucrose & $8.86 \pm 0.60$ & $22.50 \pm 0.39$ \\
\hline Cellulose & $8.84 \pm 0.40$ & $9.620 \pm 0.86$ \\
\hline Starch & $10.1 \pm 0.40$ & $10.88 \pm 1.56$ \\
\hline Yeast extract (control) & $9.02 \pm 0.20$ & $23.54 \pm 1.24$ \\
\hline Peptone & $8.10 \pm 0.20$ & $15.06 \pm 1.12$ \\
\hline Casein & $7.46 \pm 0.20$ & $12.36 \pm 0.70$ \\
\hline Soy bean meal & $12.2 \pm 1.80$ & $12.01 \pm 0.46$ \\
\hline Ammonium chloride & $9.66 \pm 1.00$ & $17.33 \pm 1.92$ \\
\hline Ammonium sulfate & $10.6 \pm 0.60$ & $12.19 \pm 1.77$ \\
\hline Sodium nitrate & $8.52 \pm 0.40$ & $25.41 \pm 1.61$ \\
\hline Potassium nitrate & $9.24 \pm 1.40$ & $23.67 \pm 1.41$ \\
\hline
\end{tabular}




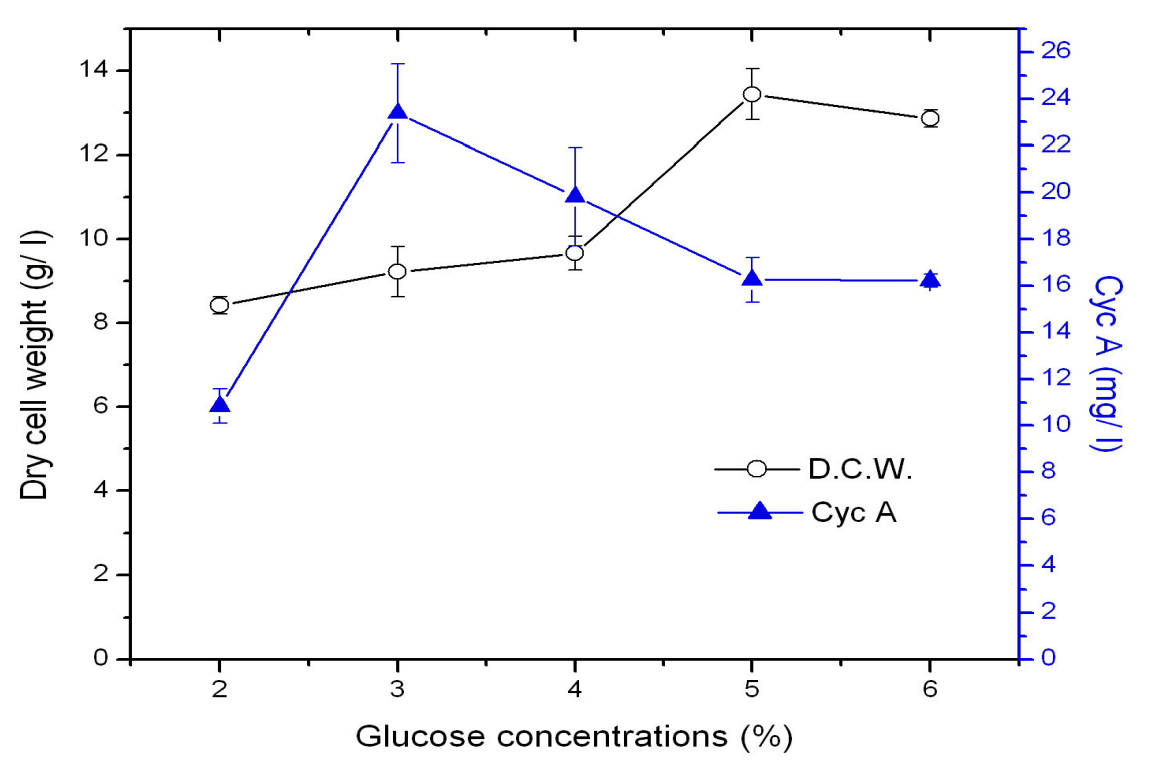

Figure 6. Effects of glucose concentrations on cell growth and Cyc A production. The media contained $0.5 \%$ (w/v) of yeast extract as a nitrogen source.

Effects of Sodium Nitrate Concentrations: Various concentrations of sodium nitrate $(0.05,0.1,0.2,0.3$ and $0.4 \%$, $\mathrm{w} / \mathrm{v})$ were added to media containing $3.0 \%(\mathrm{w} / \mathrm{v})$ glucose. When $0.2 \%$ sodium nitrate was used, maximum values of dry cell weight $(\simeq 8.64 \mathrm{~g} / \mathrm{l})$ and Cyc A $(\simeq 27.43 \mathrm{mg} / \mathrm{l})$ were obtained, afterwhich a decrease was observed in both parameters on increasing the sodium nitrate concentration (Figure 7). These results showed that the optimum carbon/ nitrogen ratio $(\mathrm{C} / \mathrm{N})$ of the broth medium should be equivalent to 15: 1 for achieving the highest production of Cyc A by $F$. roseum.

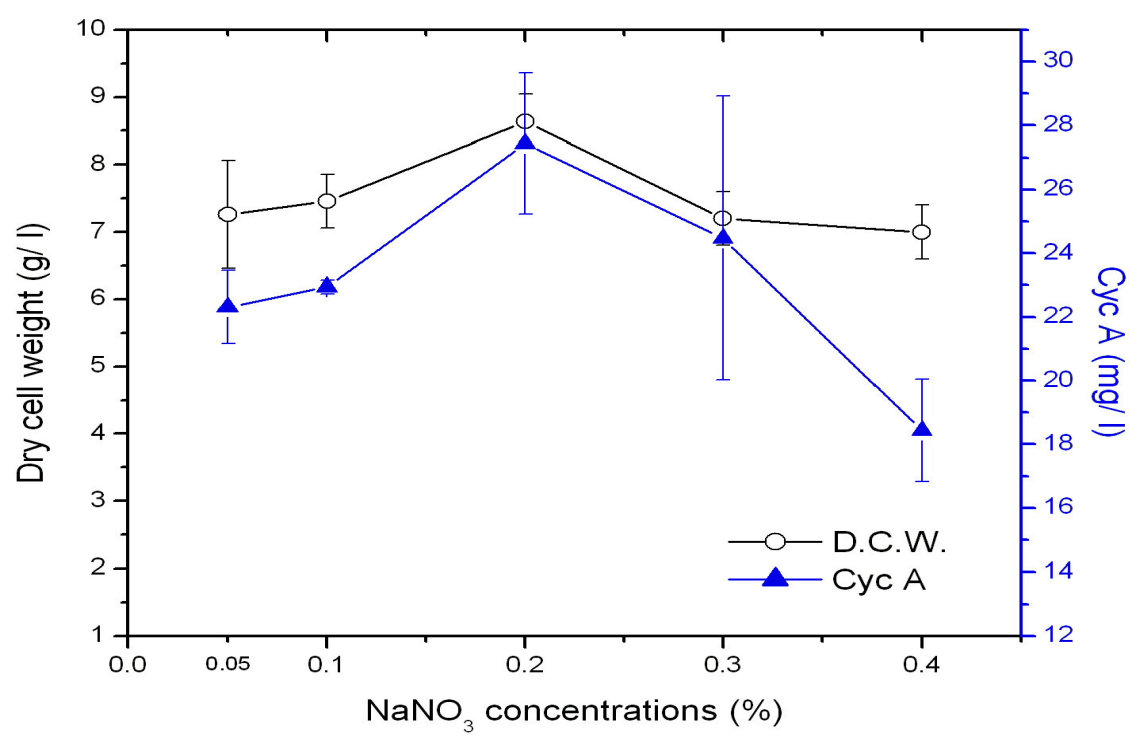

Figure 7. Effects of $\mathrm{NaNO}_{3}$ concentrations on cell growth and Cyc A production. The media contained $3.0 \%$ (w/v) of glucose as a carbon source. 


\section{DISCUSSION}

Results of different experiments to determine suitable and chemically defined broth medium for the production of Cyc A, reported to be immunosuppressive compound that has been widely used to diminish transplant rejection, reveal that a medium of the following composition was suitable for this purpose: glucose, 30; $\mathrm{NaNO}_{3}, 2 ; \mathrm{KH}_{2} \mathrm{PO}_{4}, 1 ; \mathrm{MgSO}_{4} .7 \mathrm{H}_{2} \mathrm{O}$, $0.5 ; \mathrm{KCL}, 0.5(\mathrm{~g} / \mathrm{l})$ and $\mathrm{pH}$ adjusted to 6.0. The size of the fermentation medium up to $50 \mathrm{ml} / 250 \mathrm{ml}$ flask inoculated with 5 fungal agar discs ( $6 \mathrm{~mm}$, diameter) of 7 days old of $F$. roseum culture and the incubation at $30^{\circ} \mathrm{C}$ at $120 \mathrm{rpm}$ for 7 days were the optimum conditions for the production of Cyc A. Some Fusarium species were reported to produce Cyc A, as F. solani $(28,29), F$. oxysporum (28), however no reports have not yet been studied on the production of Cyc A by F. roseum.

The main spectral features are typical for Cyc A: seven Nmethyls, four $\mathrm{N}-\mathrm{H}$ and one $\mathrm{O}-\mathrm{H}$ were observed in ${ }^{1} \mathrm{H}$ NMR analysis. Similar results were obtained by Ramana Murthy et al. (26). The data in Table 1 agree with that reported by Buchta et al. (9) on [Ala $\left.{ }^{2}, \mathrm{val}^{11}\right]$ cyclosporin, is analogous derivative of Cyc A from Mycelium sterilae.

A number of broth media have been used for production of Cyc A. Isaac et al. (18) used medium consisted of sorbose (2 $\%)$, vitamin assay Casamino acids $(1 \%), \mathrm{KH}_{2} \mathrm{PO}_{4}(1 \%)$ and $\mathrm{KCL}(0.5 \%)$ for maximum production of Cyc A from $T$. inflatum, however, Balaraman and Mathew (4) used medium containing: glucose $(8 \%)$, casein acid hydrolysate $(3 \%)$, malt extract $(2 \%)$, peptone $(1 \%)$ and DL- $\alpha$ amino butyric acid $(0.5$ $\%)$ for maximum production of Cyc A by Tolypocladium species. Formulation of the medium composed of glucose $(5$ $\%)$, bactopeptone (1 \%), $\mathrm{KH}_{2} \mathrm{PO}_{4}(0.5 \%)$, KCL $(0.25 \%)$ proved to be suitable for production of Cyc A $(2,28)$.

Most reports have been made of the production of Cyc A in the culture filtrates $(1,12,14,18,21,29)$. However we found two papers reported the extraction of $\mathrm{Cyc}$ A from the culture filtrates and mycelia of both Tolypocladium species (4) and Aspergillus terreus (28). Our results showed that high concentration of the synthesized Cyc A by $F$. roseum was produced in the fungal culture filtrate and a lower level was produced in the fungal mycelia.

In the present study, it was observed that the agitation rate at $200 \mathrm{rpm}$ showed an increase in fungal pellets more than those recorded in case of the agitation rate at $120 \mathrm{rpm}$. This result agrees with that stated by Sallam et al. (28). The maximum Cyc A yield was obtained at $120 \mathrm{rpm}$. The same agitation rate was used by Moussaif et al. (23) for maximum production of cyclosporin by Acremonium luzulae. The production of Cyc A is mainly carried out by submerged fermentation $(3,25)$. Zocher et al. (38) used $115 \mathrm{rpm}$ for Cyc A biosynthesis from T. inflatum. Kobel and Traber (19) used 180 rpm for the maximum production of Cyc A, while Evers et al. (15) used $200 \mathrm{rpm}$ for maximum cyclosporin production.

Our results showed that Cyc A was produced by $F$. roseum in maximum yields at $\mathrm{pH} 6$ of the broth medium and after incubation at $30{ }^{\circ} \mathrm{C}$ for 7 days. Abdel-Fattah et al. (1) adjusted the cultivation medium to $\mathrm{pH} 5.9$ for maximum production of Cyc A from T. inflatum after incubation at $27^{\circ} \mathrm{C}$. Additionally, Kobel and Traber (19), Chun and Agathos (10) and Manuela et al. (22) showed that the best yield of Cyc A was obtained at $\mathrm{pH}$ 5.7. Some reports used the incubation temperature at $27^{\circ} \mathrm{C}$ for production of Cyc A $(18,28,38)$. The maximum Cyc A production has been reported to vary with respect to the fermentation time course, where Sakamoto et al. (27) found that the best time span for Cyc A production was 10 days, Isaac et al. (18) found that 12 days of growth is a good period for Cyc A production from T. inflatum UAMH 2472. On the other hand, Traber et al. (34) found that 14 days is the best period for maximal production of Cyc A from T. inflatum NRRL 8044. Our data revealed that maximum production of Cyc A was obtained after 7 and 9 days, respectively; then decreased after 9 days and gave the same relative levels at the fermentation period (10-14 days) then decreased after 16 days of incubation.

Cyc $\mathrm{A}$ is not generally produced during the vegetative mycelial growth stage, but is generated only in the later pellet production stage (19). Our study showed that Cyc A production is affected by the number of inoculated fungal agar discs and medium size. A $250 \mathrm{ml}$ flask containing production medium 
equal to $50 \mathrm{ml}$ afforded the highest relative yield of Cyc A. In accordance with this result Abdel-Fattah et al. (1) and Lee et al. (21) used the same volume of the production medium. However, Zocher et al. (38) and Agathos et al. (2) found that $250 \mathrm{ml}$ flask containing $100 \mathrm{ml}$ production medium gave the highest Cyc A yield. The optimum size of the inoculum for the highest Cyc A production was varied in the previous studies, where some reports showed that $3 \%$ of spore inoculum generated the highest level of Cyc A productivity (21). However Chun and Agathos (11) and Abdel-Fattah et al. (1) used $5 \%$ inoculum size for Cyc A production, others reports showed that the best yields of Cyc A were obtained at $10 \%$ inoculum size $(2,19)$. In our study we found that the maximum concentration of Cyc A was obtained on inoculating $50 \mathrm{ml}$ production medium with 5 fungal agar discs (6 mm, diameter) of 7-days old $F$. roseum culture.

With regard to the effect of different carbon substrates on Cyc A productivity by $F$. roseum, glucose $(3 \%$, w/v) was found to be the most favourable source for production of the highest concentration of Cyc A. These results were found to be parallel to those of many reports which showed that glucose as a carbon source $(2-3 \%)$ is the most suitable source for the highest production of Cyc A $(3,4,11,26,31)$, however, Isaac et al. (18) found that sorbose (2\%) followed by glucose (2\%) were the most favorable carbon sources for maximum production of Cyc A by T. niveum UAMH 2472.

Most previous studies showed that peptone (1\%, w/v) was the most optimum nitrogen source for production of the best yield of Cyc A from Tolypocladium species (3, 4, 11, 31, 32), however Isaac et al. (18) found that $1 \%$ vitamin assay Casamino acids was the optimum nitrogen source for maximum productivity of Cyc A by T. niveum UAMH 2472, although casitone or peptone gave good yields. In our study we found that the highest Cyc A productivity (ranged from 25.41 to $27.43 \mathrm{mg} / 1$ ) was obtained from $F$. roseum by using sodium nitrate $(0.2 \%, \mathrm{w} / \mathrm{v})$ and the Cyc A concentration produced in the presence of peptone was approximately, 59.3\% of that produced in the presence of sodium nitrate, as nitrogen sources. A previous study (29) reported that Cyc A concentration of 2.5 $\mathrm{mg} / 1$ was produced by $F$. solani in potato dextrose broth and lower yields were obtained in Richard broth.

In conclusion, the present study investigated the selection of cultivation medium that resulted in enhancing the production of Cyc A by $F$. roseum, a new Cyc A-producing isolate. In addition, some optimal nutritional and physicochemical conditions for the production of Cyc A were also described. It was observed that the highest productivity of Cyc A was maintained when the fermentation process was carried out using a medium formulation composed of (g/ 1): glucose, 30; $\mathrm{NaNO}_{3}, 2 ; \mathrm{KH}_{2} \mathrm{PO}_{4}, 1 ; \mathrm{MgSO}_{4} .7 \mathrm{H}_{2} \mathrm{O}, 0.5 ; \mathrm{KCL}, 0.5$, pH 6.0, in a size up to $50 \mathrm{ml} / 250 \mathrm{ml}$ capacity flask, inoculated with five agar discs (6 mm, diameter) of 7 days old $F$. roseum culture, and incubated at $120 \mathrm{rpm}$ for 7 days.

\section{ACKNOWLEDGEMENTS}

The authors thank Prof. Dr. Ezzat, S.M. (Botany Department, Faculty of Science, Zagazig University, Egypt) for valuable advice and constructive criticism during progress of this work and Helmy, A.R., assistant lecturer of organic chemistry (Chemistry Department, Faculty of Science, Zagazig University, Egypt) for his critical comments on the results of ${ }^{1} \mathrm{H}$ NMR analysis.

\section{REFERENCES}

1. Abdel-Fattah, Y.R.; El Enshasy, H.; Anwar, M.; Omar, H.; Aboelmagd, E. (2007). Application of factorial experimental designs for optimization of cyclosporine A production by Tolypocladium inflatum in submerged culture. J. Microbiol. Biotechnol. 17 (12), 1930- 1936.

2. Agathos, S.N.; Marshal, J. W.; Marati, C.; Parekh, R.; Modhosingh, C. (1986). Physiological and genetic factors for process development of cyclosporin fermentation. J. Ind. Microbiol. 1, 39- 48.

3. Balakrishnan, K.; Pandey, A. (1996). Influence of amino acids on the biosynthesis of cyclosporin A by Tolypocladium inflatum. Appl. Microbiol. Biotechnol. 45, 800- 803.

4. Balaraman, K.; Mathew, N. (2006). Optimization of media composition for the production of cyclosporin A by Tolypocladium species. Indian J. Med. Res. 123, 525- 530.

5. Billich, A.; Zocher, R. (1987). Enzymatic synthesis of cyclosporin A. J. Biol. Chem. 262, 17258- 17259.

6. Beauchesen, P.R.; Chung, N.S.; Wasan, K.M. (2007). Cyclosporine A: a review of current oral and intravenous delivery systems. Drug Dev. Ind. Pharm. 33, 211- 220. 
7. Borel, J. F. (1986). Cyclosporin and its future. Prog. Allergy. 38, 9-18.

8. Booth, C. (1971): The genus Fusarium. Commonwealth, Mycological Institute, Kew Surrey, England.

9. Buchta, M.; Jegorov, A.; Cvak, L.; Havlíček, V.; Buděšínský§; Sedmeara, P. (1998). A cyclosporin from Mycelium sterilae. Phytochem. 48 (7), 1195-1198.

10. Chun, G..T.; Agathos, S.N. (1989). Immobilization of T. inflatum spores into porous celite beads for cyclosporin A production. J. Biotechnol. 9, 237- 254 .

11. Chun, G..T.; Agathos, S.N. (1991). Comparative studies of physiological and environmental effects on the production of cyclosporin $\mathrm{A}$ in suspended and immbolized cells of Tolypocladium inflatum, Biotechno. Bioeng. 37, 256- 265.

12. Dreyfuss, M.; Härri, E.; Hofmann, H.; Kobel, H.; Pache, W.; Tscherter, H. (1976). Cyclosporin A and C. New metabolites from Trichoderma polysporum (Link ex Pers.) Rifai. Eur. J. Appl. Microbiol. 3, 125-133.

13. Domsch, K.H.; Gams, W.; Anderson T.- H. (1980). Compendium of Soil Fungi, Vol.1, Academic Press, A subsidiary of Horcourt, Brace, Jovanovich Publishers, London.

14. El-Enshasy, H.; Abdel-Fattah,Y.; Atta, A.; Anwar, M.; Omar, H., Abou El Magd, S.; Abou Zahra, R. (2008). Kinetics of cell growth and cyclosporin A production by Tolypocladium inflatum when scaling up from shake flask to bioreactor. J.Microbiol. Biotechnol. 18 (1), 128-134.

15. Evers, M.; Migrani, S.; Carri, J.; Christophe, E. (1999). Preparation of novel cyclosporins derivatives and pharmaceutical composition. Ind. Appl. Microbiol. 49, 193.

16. Gams, W. (1997). Tolypocladium. Eine Hyphomycetengattung mit geschwollenen Phialiden. Persoonia. 6, 185- 191.

17. Heitman, J.; Movva, N.R.; Hall, M.N. (1992). Proline isomerase at the crossroads of protein folding, signal transduction and immunosuppression. New Biol. 4, 448- 460.

18. Issac, C.E.; Jonse, A.; Pickard, M.A. (1990). Production of cyclosporins by Tolypocladium niveum strains. Antimicrob. Agents Chemother. 34 (1), 121- 127.

19. Kobel, H.; Traber, R. (1982). Directed biosynthesis of cyclosporins. Eur. J. Appl. Microbiol. Biotechnol. 14, 237- 240.

20. Lawen, A.; Zocher, R. (1990). Cyclosporin synthetase. The most complex peptide synthesizing multienzyme polypeptide so far described. J. Biol. Chem. 256, 11355- 11360 .

21. Lee, M.J.; Lee, H.N.; Han, K.; Kim, E.S. (2008). Spore inoculum optimization to maximize cyclosporin A production in Tolypocladium niveum. J. Microbiol. Biotechnol. 18 (5), 913-917.

22. Manuela, O.; Gerhard, S.; Klaus, T.; Zhaung, S.; Hanspecter, M.; Rene, T.; Elisabeth, S. (1996). Biosynthesis of the unusual aminoacid (4R)4[(E)-2-butenyl]-4-methyl-L-theronin of cyclosporin A. Enzymatic analysis of the reaction sequence including identification of the methylation precursor in a polyketide pathway. Biochem. 35, 8401- 8412 .

23. Moussaïf, M.; Jacques, P.; Schaarwächter, P.; Budzikiewicz, H.; Thonart, P. (1997). Cyclosporine $\mathrm{C}$ is the main antifungal compound produced by
Acremonium luzulae. Appl. Environ. Microbiol. 63 (5), 1739- 1743.

24. Nakajima, H.; Hamasaki, T.; Nishimura, K.; Kimura, Y.; Udagawa, S.; Sato, S. (1988). Isolation of 2-acetylamino-3-hydroxy-4-methyl-oct-6enoic-acid,a derivative of the " $\mathrm{C}_{9}$ amino acid" residue of cyclosporins, produced by the fungus Neocosmospora varinfecta E.F. Smith. Agric. Biol. Chem. 52, $1621-1623$.

25. Pitchard, D.I. (2005). Sourcing a chemical succession for cyclosporin from parasites and human pathogens. Drug Discovery Today. 10, 688691.

26. Ramana Murthy, M.V.; Mohan, E.V.S.; SadhuKhan, A.K. (1999). Cyclosporin A production by Tolypocladium inflatum using solid state fermentation. Process Biochem. 34, 269- 280.

27. Sakamoto, K.; Tsujii, E.; Miyauchi, M.; Nakanishi, T.; Yamashita, M.; Shigematsu, N.; Tada, T.; Lzumi, S.; Okuhara, M. (1993). FR 901459, a novel immunosuppressant isolated from Stachybotrys chartarum No 19392. J. Antibiot. 46, 1788- 1798.

28. Sallam, L.A.R.; El-Refai, A.H.; Hamdy, A.A.; El-Minofi, H.A.; AbdelSalam, I.S. (2003). Role of some fermentation parameters on cyclosporine A production by a new isolate of Aspergillus terreus. J. Gen. Appl. Microbiol. 49, 321- 328.

29. Sawai, K.; Okuno, T.; Tereda, Y.; Harada,Y.; Wawamura, K.; Sasaki, H.; Takao, S. (1981). Isolation and properties of two antifungal substances from Fusarium solani. Agric. Biol. Chem. 45, 1223- 1228.

30. Schmidt, B.; Reisner, D.; Lawen, A.; Kleinkauf, H. (1992). Cyclosporin synthetase is a 1.4 M Da multienzyme polypeptide. Re-evaluation of the molecular mass of various peptide synthetases. FEBS Lett. 307, 355- 360.

31. Sekar, C.; Rajasekar, V.W.; Balaraman, K. (1997). Production of cyclosporin by solid state fermentation Bioprocess. Eng. 17, 257- 259.

32. Sekar, C.; Balaraman, K. (1998): Optimization studies on the production of cyclosporin A by solid state fermentation. Bioprocess Eng. 18, 293296

33. Sumegi,V.; Haszon, I.; Bereczki, C.; Papp, F.; Turi, S. (2008). Long-term follow-up after cyclophosphamide and cyclosporine A therapy in steroiddependant and resistant nefrotic syndrome. Pediatr. Nephrol. 23, 10851092.

34. Traber, R.; Hofmann, H.; Kobel, H. (1989). Cyclosporins, new analogous by precursor directed biosynthesis. J. Antibiot. 40: 591- 597.

35. Von Arx, J.A. (1986). Tolypocladium, a synonym of Beauveria. Mycotaxon. 25, 153- 158.

36. Zhou, X.; Hu, Y.; Tian, Y.; Hu, X. (2009). Effect of N-trimethyl chitosan enhancing the dissolution properties of the lipophilic drugs cyclosporin A. Carbohydrate Polymers. 76, 285- 290.

37. Zocher, R.; Madry, N.; Peeter, H.; Klienkauf, H. (1984). Biosynthesis of cyclosporin A. Phytochem. 23, 549- 551.

38. Zocher, R.;Nihira, T.; Paul, E.; Madry, N.; Peeters, H.; Kleinkauf, H.; Keller, U. (1986). Biosynthesis of cyclosporin A: Partial purification and properties of a multifunctional enzyme from Tolypocladium inflatum. Biochem. 25; 550- 555. 